\title{
SCIENCE.-Supplement.
}

FRIDAY, JANUARY 14, 1887.

\section{ON THE ENRICHMENT OF THE SOIL BY THE CULTIVATION OF' 'ENRICHING CROPS.'}

IT is an observation almost as old as agriculture, - certainly much older than the earliest literature of agriculture, - that certain crops appear to increase the fertility of the soil upon which they are grown; or, to state the case more accurately, they exert a favorable influence upon the growth of the succeeding crop. Red clover is the typical example of such a crop; and the use of this plant as a means of renovating poor or exhausted ${ }^{-}$soils is co-extensive with improved agriculture. Other crops, on the contrary, have an opposite effect, and are denominated exhausting, as, for example, the cereals.

But while the facts just recounted are sufficiently well known, their cause or causes are by no means so well made out. The first attempts at explanation naturally assumed that the exhausting crops took more from the soil than the enriching crops, or, what amounts to the same thing, that the latter were the medium of conveying materials from the atmosphere to the soil. The enriching crops were also supposed to improve the soil by facilitating the direct acquisition of material by the soil from the air, accomplishing this by shading the soil, by the mechanical action of their roots, and also, in case of root-crops, for example, by the tillage necessary for their cultivation.

Thaer and his school, to whom we owe these attempts at explanation, considered the humus of the soil to be the real food of the plants, and the mineral matters to be unessential, and naturally found support for their hypotheses in the great increase in the organic matter or humus of the soil consequent upon the growth of such a crop as clover, for example. As the progress of investigation brought about a better understanding of the laws of vegetable nutrition and the sources of plant-food, these views as to the action of enriching crops were gradually modified; but they continued, and still continue, to follow the general lines laid down by Thaer. We now know that the plant obtains from the soil its mineral ingredients and its nitrogen, while the bulk of its 'organic' matter is assimilated by its leaves. It is plainly impossible that a crop should enrich the soil in mineral matters. All crops enrich the soil in carbon to some extent, since their roots and stubble remain in the soil ; but this carbon appears to be of no direct use to the plant. There remains only the nitrogen, and the modern theories of the action of enriching crops are based on the belief that they somehow increase the store of nitrogen in the soil. Indeed, if we substitute nitrogen for humus in Thaer's hypotheses, we have very nearly the views of recent authors.

Before proceeding to discuss these views, however, it will be well to inquire whether this supposed enrichment of the soil is a fact. The benefits of a judicious rotation of crops are undoubted, but they are susceptible of a variety of explanations. A crop like clover, for example, may promote the growth of a succeeding grain-crop in a variety of ways, having no relation to the stock of nitrogen in the soil. Only careful scientific experiments can decide whether such crops actually enrich the soil in nitrogen. Unfortunately, but few experiments upon this subject have as yet been made, and some of those reported are of doubtful value. Considerable interest, therefore, attaches to the experiments made by Strecker in the year 1883-84 at Göttingen, an account of which has recently been published, ${ }^{1}$ along with a very complete review of the literature of the subject.

Strecker experimented upon plants and soils in pots, lupines serving to represent the legumes, and oats the cereals. But one of the vegetation experiments of 1883 succeeded ; viz., one with lupines in unmanured sand. From the data given, it appears that the soil and roots remaining in the pot contained only about 40 per cent of the nitrogen originally present in the sand, or introduced .a the seed or in the rain to which the pots were exposed. On the other hand, the amount thus removed from the soil was only about 39 per cent of the total quantity found in the aerial portions of the plants : the remaining 61 per cent, therefore, must either have been assimilated directly from the atmosphere or been absorbed from it by the soil. Six pots without plants were also exposed during the summer; and these showed, without exception, a considerable loss of nitrogen, which, as there was no drainage from the pots, must have passed off into the air. Two of the pots contained unmanured sand with 0.0015 per cent of nitrogen ; and the variations in these were evidently within the limits of analytical error and of

1 Journ. f. landw., xxxiv. 1. 
no significance. The other four pots contained the same sand manured with bone-dust, and these showed an unmistakable loss of nitrogen. This loss, of course, was from the manure rather than from the soil, and it seems probable that it was due to the loss of nitrogen in the free state during decay which has been shown to occur by Reiset, Lawes and Gilbert, König and Kieson, Dietzell, Morgen, and others, including the writer. At the same time, these results show that this loss may take place under the circumstances in which organic matter exists in the soil or in the added manure. Strecker observed that the loss was less when the soil was stirred on the surface than when undisturbed, and greater in the sun than in the shade. He explains the former fact by the hypothesis that the loosened soil absorbed ammonia from the air more freely than the compact one, and thus made good part of the loss just noted.

The experiments of 1884 were made partly in glass pots, and partly in zinc boxes. Both stood under cover, protected from both rain and dew. Some were filled with sand, and some with garden-soil. As before, lupines and oats were used as experimental plants, and pots were also left without plants for the purpose of observing the loss of nitrogen noted in the previous year's experiments.

Strecker's principal conclusions from his results were as follows :-

1. A naked soil exhales during the summer considerable quantities of nitrogen. The loss is greater from compact than from stirred soil. The results of the experiments of 1884 upon this point were of the same character as those of 1883 ; that is, the results in the sand alone are of no significance, while those in the manured sand show in reality a loss of nitrogen by the manure. In addition to this, however, one of the pots with garden-soil showed an unmistakable loss of nitrogen.

2. If the soil is occupied by oats or lupines, this loss of nitrogen is diminished. Some loss was still observed in most cases; but when lupines were grown in unmanured sand, the results, calculated on the basis of the minimum percentage of nitrogen originally found in the sand, showed a gain of nitrogen by the soil and roots. An unmistakable increase of the nitrogen of soil and plant over that of soil and seed was noted in several of these trials in unmanured sand.

3. In all cases in which the soil was tolerably rich in nitrogen, less nitrogen was found in it after the growth of a crop and the removal of the aerial portions than was present at the beginning of the experiment: in other words, there was no enrichment of the soil.
4. No essential difference. was observed between lupines and oats. Both drew their supply of nitrogen from the soil, and, in most if not all cases, left it poorer than they found it.

It will be seen that Strecker's experiments give little countenance to any hypothesis of a gain of nitrogen from the atmosphere. In this respect they differ from the results reported by Atwater. ${ }^{1}$

The latter experimented upon peas grown in sand and watered with a solution of plant-food, and found in nearly every case much more nitrogen in soil and plant than was supplied in seed and nutritive solution. His results, however, do not bear directly upon the question under discussion, because he removed the whole plant, including the roots, from the soil, and determined only the total nitrogen in roots and tops and the residual nitrogen of the soil. It would seem, however, that, if plants can gain so large a proportion (up to 50 per cent) of their nitrogen from the air as they did in these experiments, they might very well enrich the soil in nitrogen through their roots and stubble. Strecker's experiments are very interesting as regards the relations of soil and plant to the nitrogen supplies of the atmosphere, but they are entirely inadequate to explain the functions of 'enriching crops' in agriculture. Pot experiments, while they permit any exchange of nitrogen between crop and atmosphere to be accurately observed, practically assume that the soil ends at the depth of ten or twelve inches, and take no account of the subsoil as a source of nitrogen. They thus ignore a factor of great importance, and one which affects the question in two distinct ways. In the first place, large amounts of nitrates may escape into the subsoil with the drainage-water. I have discussed in an earlier article (Science, iii. No. 48), the results of experiments by Lawes and Gilbert and by Dehérain, bearing on this subject, and have shown that the deep-rooting leguminosae, which have a long growing-season, have an important function in arresting these nitrates, and storing them up in an insoluble form, to be set free again gradually for the use of a succeeding crop. According to Lawes and Gilbert, it is at least probable that the roots of clover in some way serve to convey the nitric ferment into the subsoil (which is naturally nearly destitute of it), and thus indirectly convert the insoluble nitrogen compounds there present into nitrates, which they then proceed to assimilate.

In the second place, it would appear that clover and similar deep-rooting plants may bring up nitrogen from the subsoil and deposit it in their upper roots and stubble. While the soil as a

\footnotetext{
1 Amer. chem. journ., vi. 365.
} 
whole is not enriched by this process, the surface soil is, and this concentration of nitrogen in a smaller soil area may greatly facilitate the growth of a succeeding shallow-rooting and quick-growing crop. Drechsler ${ }^{1}$ has attempted to show that such an enrichment of the surface soil is impossible. He argues, that, since the roots develop chiefly where they find food, if they find their supply of nitrogen chiefly in the subsoil, they will develop chiefly there, and consequently will not enrich the surface soil. It is not difficult to show, however, that this reasoning is fallacious. It is no more difficult to conceive that nitrogen should be transferred from the subsoil roots to the surface-soil roots, if the latter found an abundant supply of mineral matters at hand, than it is to conceive that both nitrogen and ash ingredients may be transferred from the roots to the aerial parts of the plant, provided the latter find a sufficient supply of carbon dioxide. Let us suppose the surface soil to be absolutely destitute of nitrogen to the depth of six inches, and that the nitrogen of the seed is sufficient to supply the growth of a root down into the nitrogen-bearing layers below. A plant would certainly grow under such conditions; and, when the crop was harvested, its stubble and what roots it had formed in the upper six inches of the soil would contain nitrogen, and the surface soil would be enriched to just this extent at the expense of the subsoil.

It would appear, then, that such an enrichment of the surface soil is possible. But few experiments calculated to demonstrate its actual occurrence have been made. The problem is not an easy one. It is difficult to take samples of a soil which shall be truly, average samples; and the percentage differences are so small that they may easily be hidden by an error in sampling. Analyses by Dehérain and by Lawes and Gilbert, however, appear to show that such a gain does take place.

Finally, the relative power of different plants to assimilate nitrogen has an important bearing on this question. Wagner has rendered it probable that leguminous plants are able to assimilate freely the comparatively insoluble nitrogen of the soil, while the cereals require their nitrogen in an easily soluble form. If this is true, one of the functions of enriching crops may be assumed to be to gather the nitrogen of the soil which is unavailable to other crops, concentrate it in its roots and stubble, and yield it up again by decay to the following crop.

On the whole, it does not seem difficult to account for the effects of enriching crops without

1 Journ. f. landw, xxxi. 30. supposing that they draw materially from the nitrogen of the air, while not excluding the possibility of their so doing. Whether our agriculture is flourishing, as Lawes and Gilbert maintain, at the expense of the accumulated nitrogen of past centuries, or whether there are processes by which free nitrogen is brought into combination again in quantities sufficient to balance the evolution of free nitrogen which we know to be continually going on, is as yet an unsettled question.

H. P. ARMSBy.

\section{NATURAL GAS.}

A LECTURE on the subject of natural gas was delivered at the Franklin institute on Saturday evening, Dec. 18 last, by Mr. Charles A. Ashburner, geologist in charge of the State geological survey. The lecturer stated that natural gas was by no means a recent discovery. Even its utilization for the purposes of the mechanic arts had been successfully attempted in China, where, by pipes of bamboc, it had been conveyed from natural wells to suitable furnaces, where, by means of terra-cotta burners, it was consumed. In the confines of Persia, in the south of France, and in our own western states, burning-springs bad long been known. When Lafayette visited this country in 1821, the inn in the town of Fredonia, N. Y., was illuminated in his honor by gas procured from a neighboring well. It is, however, only within recent years that natural gas has arisen to any importance in its bearing on the mechanic arts. At present the great iron and glass works of Pittsburg and of other places are supplied with natural gas as their only fuel, and millions of cubic feet are yearly consumed in Pittsburg and similarly situated cities.

Of the origin of natural gas there seems to be no reasonable doubt. It arises from the decomposition of forms of animal or vegetable life embedded in the rocks in suitable situations. The gas is not believed to be generated continuously, but merely to be stored in porous or cavernous rocks overlaid by impervious strata. When these collections are tapped, the gas is set free, but a new supply is not being formed to take its place. The position at which the gas is found is very variable, depending upon the force of gravity and upon the position of the porous layer in which the gas is confined. The lecturer entered into an accurate description of the localities in which the gas was found, and gave the reasons why it was hopeless, from geological grounds, to look for natural gas east of the Alleghenies. The region in which the gas is found is practically embraced in that portion of Pennsylvania west of the Alle- 